\title{
Effect of blood transfusion on cardiorespiratory abnormalities in preterm infants
}

\author{
H Stute, B Greiner, O Linderkamp
}

\begin{abstract}
The effects of red blood cell transfusion on the incidences of apnoea, bradycardia, tachycardia and oxygen desaturation over periods of 72 hours before and after transfusion were assessed in 25 infants with a gestational age of $\leqslant 32$ weeks (mean (SEM) $29.2(0.4)$ weeks, birthweight 1170 (73) g; postnatal age at transfusion 39 (4) days). During transfusion haemoglobin rose from 78 (2) $g / 1$ to 117 (2) g/l. Significant decreases were observed in daily frequencies of apnoeas longer than 15 seconds (median from 2.7 to 0.9 events a day), tachycardias of more than 200 beats per minute (from 34 to 25 events per day), bradycardias below 100 beats per minute (from 65 to 12 events per day) and 80 beats per minute (from 8.4 to 3.3 events per day). Oxygen saturation improved in 20 of the infants. Transfusion improves cardiorespiration in preterm infants for several days.
\end{abstract}

(Arch Dis Child 1995; 72: F194-F196)

Keywords: blood transfusion, cardiorespiratory abnormalities.

Seventy per cent of premature infants with birthweights below $1500 \mathrm{~g}$ receive at least one red blood cell transfusion. ${ }^{1}$ Indications for transfusion in premature infants include anaemia at birth, blood losses due to blood sampling, and insufficient erythropoiesis. Symptoms and signs of anaemia in premature infants include poor feeding and weight gain, lethargy, pallor, acidaemia and cardiorespiratory abnormalities, such as increased frequencies of apnoea, bradycardia, tachycardia and oxygen desaturation. ${ }^{2} 3$

Reports on the effects of red blood cell transfusion on cardiorespiratory abnormalities are conflicting. Sadsidharan and Heimler observed that transfusions significantly decreased the incidence of apnoea and periodic breathing. ${ }^{4}$ Keynes et al found no effect of transfusion on the incidence of apnoeas longer than 15 seconds and bradycardias below 100 beats per minute. ${ }^{5}$ Bifano et al observed similar effects of red blood cells and of albumin transfusion on the incidence of cardiorespiratory abnormalities over four hours, suggesting that volume expansion rather than the rise in haemoglobin improves cardiorespiratory functions. ${ }^{6}$

Previous studies on the effects of red blood cell transfusion on cardiorespiratory abnormalities in preterm infants did not consider oxygen saturation and included infants with and without complications (such as increased oxygen demand, chronic lung disease, intraventricular haemorrhage)..$^{6-9}$ Moreover, in previous investigations infants were studied only for four to 12 hours before and after transfusion. ${ }^{4-8}$ Our investigation was designed to study cardiorespiratory function in premature infants without major complications for 72 hours before and after a red blood cell transfusion.

\section{Methods}

Twenty five preterm infants were included in the study. Inclusion criteria were: haemoglobin concentration below the limit shown in table 1 ; gestational age below 33 weeks; treatment with theophylline and a plasma theophylline concentration of 6 to $12 \mu \mathrm{g} / \mathrm{dl}$. During the three day recording before transfusion, infants had one or several of the following cardiorespiratory abnormalities: at least one apnoea of more than 15 seconds, one bradycardia of less than 80 beats per minute for more than 5 seconds, or 20 tachycardias of more than 200 beats per minute. Each infant was studied only once.

Excluded were infants with infection, congenital heart disease, malformations, cardiac arrhythmia, intraventricular haemorrhage, seizures, in receipt of sedatives, metabolic disorders or severe airway obstruction and a requirement for oxygen.

The premature infants received $10 \mathrm{ml}$ of red blood cells per $\mathrm{kg}$ of body weight over three hours. Apnoeas, bradycardias, and tachycardias were documented on a four-channel event recorder (Edentec 2000W, Minneapolis, USA) during periods of 72 hours before and after transfusion. The four channels were used for recording of respiration rate, heart rate, oxygen saturation and electrocardiogram (ECG) (figure). For each event (defined as an apnoea of more than 15 seconds, bradycardia less than 100 beats per minute or tachycardia of more than 200 beats per minute) respiration

Table 1 Number of indications for erythrocyte transfusion in premature and term infants

\begin{tabular}{lll}
\hline $\begin{array}{l}\text { Age } \\
\text { (weeks) }\end{array}$ & $\begin{array}{l}\text { Premature infants } \\
\text { haemoglobin }(g /)\end{array}$ & $\begin{array}{l}\text { Term neonates } \\
\text { haemoglobin }(g /)\end{array}$ \\
\hline 1 & $120(140)$ & $110(130)$ \\
2 & $110(130)$ & $100(120)$ \\
3 & $100(120)$ & $90(110)$ \\
4 & $90(110)$ & $80(100)$ \\
5 & $80(100)$ & $70(90)$ \\
$>5$ & $70(100)$ & $70(90)$ \\
\hline
\end{tabular}

Values in parentheses: $\mathrm{FIO}_{2}$ of $\geqslant 30 \%$, ventilation, tachycardia, tachypnoea, poor weight gain, poor feeding and lethargy, tachypnoea, poor weight gain, poor feee
persistence of apnoeas or bradycardias. 

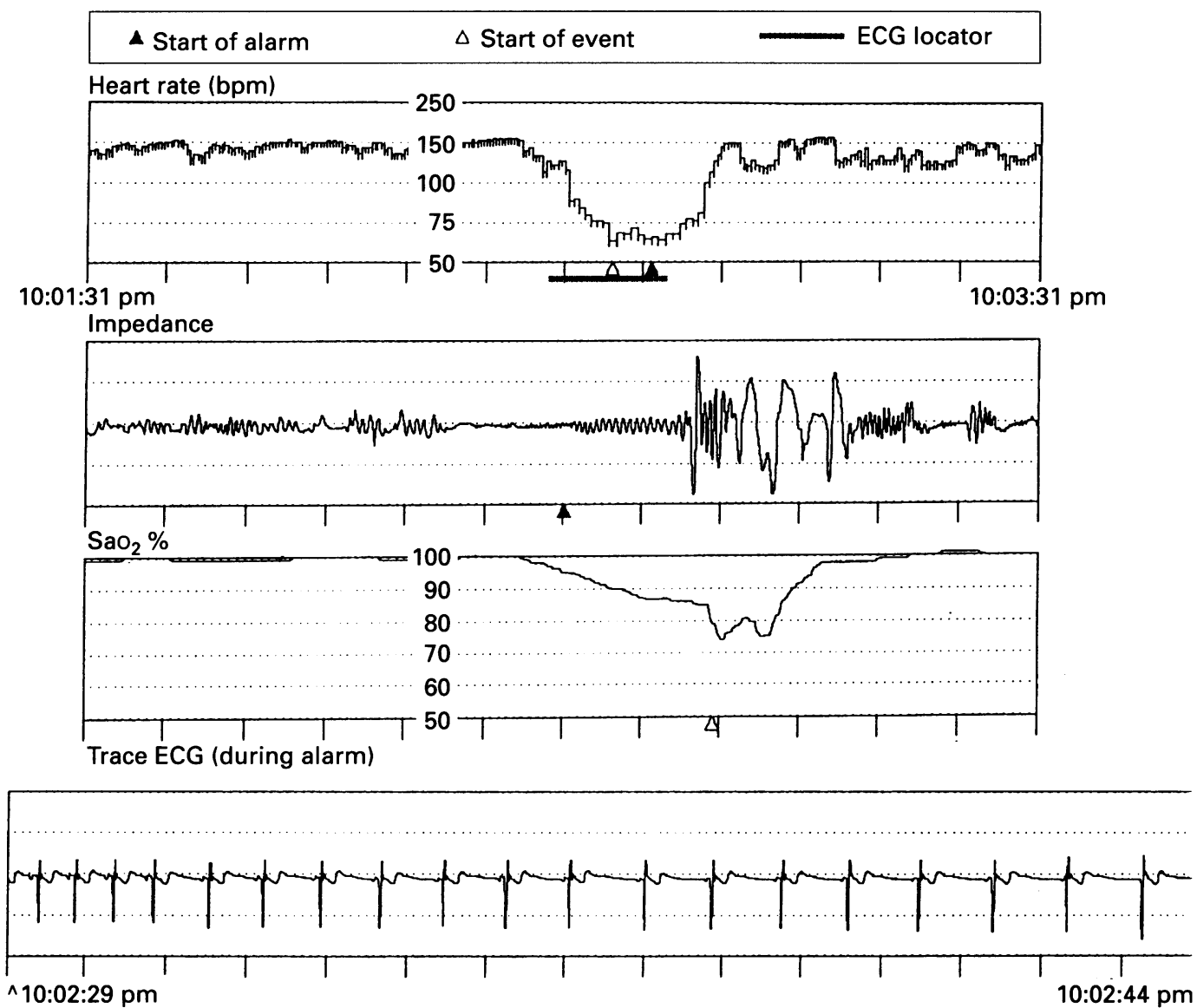

Event recording of two minutes in a preterm infant, showing apnoea, bradycardia, and oxygen desaturation.

rate, heart rate and oxygen saturation were continuously documented for two minutes, one minute before and one minute after the event. The ECG was recorded at each event for 15 seconds during the period of lowest heart rate. These waveforms were displayed on a computer or printed (figure). In addition to the continuous two-minute recordings, the following events were listed: periodic breathing and apnoeas of 10 to 15 seconds.

No event recording was done on the day of transfusion. Haemoglobin concentration was measured before transfusion and 10-14 hours afterwards.

Each two minute recording was analysed manually. Type of event, duration and extent of bradycardias, duration and probable cause of apnoeas (central or non-central ${ }^{10}$ ) were evaluated. False events caused by low impedance, movements, and other artefacts were excluded. Apnoeas of 10 to 15 seconds and periodic breathing were not displayed and could therefore not be corrected.

The data were exported and analysed by APL Statgrafics 2.6. For each parameter and day mean, standard deviation and median were calculated. A paired Wilcoxon-rank test was used to analyse the effects of transfusion and day to day changes of all parameters.

\section{Results}

During transfusion haemoglobin concentration rose from 78 (2) $\mathrm{g} / \mathrm{l}$ (mean (SEM), range 62 to 99 ) to 117 (2) $\mathrm{g} / \mathrm{l}$ (range 98 to 138 ; $\mathrm{p}<0.001)$. None of the cardiorespiratory parameters showed day to day changes during the three days before transfusion and during the three days after transfusion.

Table 2 presents the incidence of cardiorespiratory events in the 25 infants before and after transfusion. The incidence of apnoeas longer than 15 seconds and those of bradycardias and tachycardias decreased significantly after transfusion. Nineteen out of 25 infants showed a decrease in the number of apnoeas longer than 15 seconds, two showed no change, and two had more apnoeas of 15 seconds and longer. The number of bradycardias of less than 80 beats per minute decreased in 24 and the number of tachycardias decreased in 20. One infant showed more bradycardias, two infants showed no improvement, and two infants showed more tachycardias after transfusion. The incidence of pronounced oxygen desaturation $(<85 \%)$ decreased in 20 infants and did not change in five infants after transfusion.

\section{Discussion}

Previous studies on the effects of blood transfusion on cardiorespiratory abnormalities in preterm infants were done within 12 hours before and after transfusion. ${ }^{4-8}$ To evaluate the longer lasting effects of transfusion, we studied the infants for three days before and after transfusion. Joshi et al observed a significant reduction in periodic breathing, the number of apnoeas, bradycardias, and the 
Table 2 Effects of transfusion on incidence of bradycardia, tachycardia, respiration and oxygen saturation in 25 preterm infants

\begin{tabular}{|c|c|c|c|c|c|}
\hline & \multicolumn{3}{|c|}{ Events per day } & \multirow{3}{*}{$\begin{array}{l}\text { Number } \\
\text { of infants } \\
\text { with event } \\
\text { reduction }\end{array}$} & \multirow{3}{*}{$p$ Value } \\
\hline & \multicolumn{2}{|c|}{ Medians of transfusion } & \multirow{2}{*}{$\begin{array}{l}\text { Medians (ranges) } \\
\text { of changes }\end{array}$} & & \\
\hline & Before & After & & & \\
\hline Apnoeas $10-15$ seconds & $18 \cdot 7$ & $16 \cdot 6$ & $1(-258$ to 123$)$ & 12 & NS \\
\hline Apnoeas > 15 seconds & $2 \cdot 7$ & 0.9 & $1.7(-2$ to 8$)$ & 19 & 0.040 \\
\hline \multirow{2}{*}{\multicolumn{6}{|c|}{$\begin{array}{l}\text { Periodic breathing } \\
\text { Bradycardia }<100 \text { beats/minute }\end{array}$}} \\
\hline & & & & & \\
\hline Caused by central apnoea & $6 \cdot 7$ & $3 \cdot 8$ & $2 \cdot 8(-9$ to 14$)$ & 18 & 0.0500 \\
\hline Caused by mixed or obstructive apnoea & $65 \cdot 9$ & $12 \cdot 9$ & $18 \cdot 1(-166$ to 135$)$ & 23 & 0.0040 \\
\hline \multicolumn{6}{|l|}{ Bradycardia $<80$ beats $/$ minute } \\
\hline Caused by central apnoea & 3.9 & $2 \cdot 4$ & $1 \cdot 7(-3$ to 13$)$ & 24 & 0.0005 \\
\hline Caused by mixed or obstructive apnoea & $8 \cdot 4$ & $3 \cdot 3$ & $1 \cdot 4(-2$ to 70$)$ & 24 & 0.0003 \\
\hline Tachycardia $>200$ beats $/$ minute & $34 \cdot 1$ & 25 & $5 \cdot 3(-20$ to 52$)$ & 20 & 0.0040 \\
\hline \multirow{2}{*}{$\begin{array}{l}\text { (apnoeas and bradycardias) } \\
\text { (amum } \mathrm{O}_{2} \text { saturation during events }\end{array}$} & & & & & \\
\hline & $79 \cdot 3$ & $83 \cdot 2$ & $3 \cdot 8(-4$ to 15$)$ & & 0.001 \\
\hline $\begin{array}{l}\text { Median } \mathrm{O}_{2} \text { saturation during events } \\
\text { (apnoeas and bradycardias) }\end{array}$ & 86 & $88 \cdot 5$ & $2 \cdot 3(-3$ to 14$)$ & & 0.004 \\
\hline
\end{tabular}

mean heart rate during six hours after transfusion. ${ }^{8}$

De Maio et al reported a decrease in apnoea density and periodic breathing during four hours after blood transfusion. ${ }^{7}$ Sadsidharan and Heimler found decreases in mean heart rate, apnoeic episodes, and periodic breathing within 12 hours of transfusion. ${ }^{4}$ Keyes et al recorded heart and respiratory rate, incidence of apnoea and bradycardia clinically (without pneumocardiogram) during 6-12 hours before and after blood transfusion in preterm infants. ${ }^{5}$ They found no effect for transfusion.

Bifano et al compared the effects of blood transfusion and albumin infusion. ${ }^{6}$ Heart rate decreased only after blood transfusion and the number of bradycardias was not affected by either procedure. The reduction in six second apnoea density was similar after red blood cell transfusion and albumin infusion. They concluded that volume expansion rather than the rise in oxygen capacity reduced the number of apnoeas in preterm infants. However, the volume effect of albumin probably lasts only a few hours. Moreover, the volume effect of transfused red blood cells may also fade due to extravasation of plasma. ${ }^{11}$ Thus the continuous effect of transfusion during three days after transfusion observed in our study was probably not a result of volume expansion but rather of improved oxygen supply to the tissues.

Previous studies on the effects of blood transfusion on cardiorespiratory abnormalities in preterm infants did not consider the incidence of tachycardia, the extent of oxygen desaturation during apnoeic and bradycardic events, and day to day changes. We observed that transfusion caused a significant reduction in the number of tachycardias of more than 200 beats per minute (table 2). Minimum oxygen saturation during events was $4 \%$ higher after transfusion. This suggests that both the number and the severity of respiratory events decreased with transfusion. Day to day changes in cardiorespiratory parameters were investigated by Hunt et al. ${ }^{12}$ They found a slight (not significant) decrease in the incidences of apnoea and periodic breathing during two days of continuous recording. We found no significant changes in the cardiorespiratory parameters within three days before and after transfusion.
The increased numbers of cardiorespiratory events in anaemic preterm infants has been explained by decreased oxygen transport and supply, which predisposes tissues to hypoxia. Hypoxia is thought to depress respiratory and circulatory centres in the brain, thereby increasing the number of respiratory and cardiac abnormalities. ${ }^{13} 14$ Transfusion may increase the oxygen supply of tissues by raising the oxygen transport to various organs. ${ }^{15-18}$ Moreover, adult haemoglobin in the transfused red blood cells may facilitate oxygen unloading.

1 Strauss RG. Transfusion therapy in neonates. $A m \mathcal{F}$ is Child 1991; 145: 904-11.

2 Roberton NRC. Top up transfusions in neonates. Arch Dis Child 1987; 62: 984-6.

3 Stockman JA, Clark DA. Weight gain: a response to transfusion in selected preterm infants. Am 7 Dis Child 1984 138: 828-30.

4 Sadsidharan $\mathrm{P}$, Heimler $R$. Transfusion induced changes in breathing pattern of healthy preterm anemic infants. Pediatr Pulmonol 1992; 3: 170-3.

5 Keyes WG, Donohue PK, Spivak JL. Assessing the need fo transfusion of premature infants and role of hematocrit, clinical signs and erythropoietin level. Pediatrics 1989; 84 412-7.

6 Bifano EM, Smith F, Borer J. Relationship between determinants of oxygen delivery and respiratory abnormalities in preterm infants with anemia. $f$ Pediatr 1992; 120: 292-6.

7 DeMaio JG, Harris MC, Deuber C, Spitzer AR. Effect of blood transfusion on apnoea frequency in growing premablood transfusion on apnoea frequency in

8 Joshi A, Gerhardt T, Shandloff P. Blood transfusion effect on respiratory pattern of preterm infants. Pediatrics 1987 80: $79-84$.

9 Samuels MP, Poets CF, Stebbens VA, Alexander JR, Southall DP. Oxygen saturation and breathing patterns in preterm infants with cyanotic episodes. Acta Paediat Scand 1992; 81: 875-80.

10 Henderson-Smart DJ. Apnea of prematurity. In: Beckerman RC, Brouillette RT, Hunt CE, eds Respiratory control disorders in infants and children. Baltimore: Williams \& Wilkins, 1992: 161-77.

11 Linderkamp O. Placental transfusion: Determinants and effects. Clin Perinatol 1982; 9: 559-92.

12 Hunt CE, Brouillette RT, Liu K, Klemka L. Day-to-day pneumogram variability. Pediatr Res $1985 ; 19: 174-7$.

13 Cross KW, Oppe TE: The effect of inhalation of high and low concentration of oxygen on the respiration of the premature infant. 7 Physiol 1952; 117: 38-55.

14 Pearlman JM, Volpe JJ. Episodes of apnoea and bradycardia in the preterm infant: impact on cerebral circulation. Pediatrics 1985; 76: 333-8.

15 Holland BM, Jones JG, Wardrop CAJ. Lessons from the anaemia of prematurity. Hematol Oncol Clin North Am 1987; 1: 355-66.

16 Hudson I, Cooke A, Holland BM, Houston A, Jones JG, Turner T, Wardrop CAJ. Red cell volume and cardiac output in anaemic preterm infants. Arch Dis Child 1990 65: $672-5$.

17 Nelle M, Höcker C, Zilow EP, Linderkamp O. Effects of red cell transfusion on cardiac output and blood flow velocities in cerebral and gastrointestinal arteries in premature infants. Arch Dis Child 1994; 71: F45-8.

18 Wardrop CAJ, Holland BM, Veale A, Jones JG, Gray OP Nonphysiological anemia of prematurity. Arch Dis Child 1978; 53: 855-60. 